\title{
Viewpoints
}

\section{COVID-19 Vaccine donations: Blessings and curses for Africa}

\author{
Brenda Z. Kubheka ${ }^{1}$ (D), Tshowa Kabala² (D) \\ ${ }^{1}$ Health IQ Consulting, Johannesburg, South Africa; School of Public Health, University of the Witwatersrand, Johannesburg, South Africa, ${ }^{2}$ Health IQ \\ Consulting, Johannesburg, South Africa \\ Keywords: COVID-19, Vaccines, Africa, Funding, Access, Inequity, Economic development, policy
}

https://doi.org/10.52872/001c.30735

\section{Journal of Global Health Economics and Policy}

Vol. 2, 2022

\begin{abstract}
Africans face double jeopardy on life expectancy due to poverty and constrained vaccine access. The COVID-19 pandemic caused the 2021 crude death rate in South Africa to rise from 8.7 deaths per 1000 people in 2020 to 11.6 deaths per 1000 people in 2021 . Vaccination access is critical and depends on international solidarity and collaboration for sustainable programs. History points to the critical need for African countries to safeguard national sovereignty and prioritise donations with broader development objectives. Donor assistance should focus on assisting countries to rise and thrive beyond the pandemic challenges. Reducing benefactor dependency requires countries to be intentional about raising and securing financial resources to sustain vaccine access for the current and future generations. The assistance should focus on facilitating development, meaning investing in countries to thrive beyond the pandemic turbulence. For the sake of Africa's people and her future generations, current barriers to equitable vaccine access must be scrutinised. We do not know how many vaccine booster shots will be required in the future and the impact on Africa's health and socioeconomic standing. Global collaboration grounded on bolstering local manufacturing capacity is essential for Africa's sustainable access and distribution.
\end{abstract}

Africa is the second most populous continent, with a mean age of 19.7 years. ${ }^{1}$ The number of older Africans is expected to triple between 2020 and 2050, outpacing the rest of the world. Currently, $80 \%$ of people living on less than $\$ 1.90$ are in South Asia and sub-Saharan Africa. ${ }^{2}$ According to the World Bank, ${ }^{3}$ sub-Saharan Africa accounts for two-thirds of the global extremely poor population, and half of the countries in the region have poverty rates of more than $35 \%$.

Africa represents $14 \%$ of the world's population and yet, until April 2021, had less than $0.2 \%$ of the world's vaccine production capacity. ${ }^{4}$ Inequitable distribution and hoarding of the COVID-19 vaccine witnessed in the early days of the pandemic is linked to vaccine nationalisation, ${ }^{5}$ facilitating health inequity between rich and emerging countries. Inequitable access to immunisation could slow global economic recovery, widening health and economic gaps across regions.

Africa's estimated monthly GDP losses may amount to $\$ 13.8$ billion without vaccines. $^{6}$ It stands to reason that societies benefit from efficient vaccine programs that are context responsive and sustainable. Africa has received the highest number of COVID-19 vaccine dose donations and related funding compared to other regions. ${ }^{7}$ The socioeconomic benefits from such donations cannot be undermined, similarly, the critical role of intercontinental collaboration in improving vaccine access. However, there is a need for a stronger focus on vaccine promotion and sustainability of these vaccine programs to achieve their in- tended goals. Whilst assistance provided to African countries remains invaluable, African leaders must ensure the alignment of assistance with national development objectives. History points to a critical need for African countries to safeguard their sovereignty and avoid donation driven compromises. Africa must be intentional when it comes to accepting aid. The assistance should serve to support countries to rise and thrive beyond the pandemic pandemonium.

COVID-19 booster shots will be required to counter the waning immunity over time. High-income countries are already implementing booster vaccination programs during inequitable access and price discrimination, which negatively impacts low- and middle-income countries. The role and nature of collaborations, vaccine financing, manufacturing capacity and supply chain mechanisms for sustainable and equitable vaccine access in the region must also be attended. Notably, the question related to intellectual property (IP waivers), specifically on how these will translate into a dependable local and full manufacturing capacity. Slavery, colonisation, wars and apartheid have defined Africa's history. This backdrop has shaped Africa's economic, political, and social systems; it also colours the trust over vaccines. Improving confidence in the network of institutions responsible for vaccine funding and implementation whilst prioritising sovereignty is a higher task of national governing bodies.

Vaccine donations are necessary at this moment, but these need to be managed like a project, with clear objectives premised on saving lives, bolstering economic recov- 
ery, and building local manufacturing capacity for vulnerable African countries. Donor interests ought to be premised on shielding Africa from dependency on aid; and, instead, direct assistance towards stimulating economic development and innovation within the region. Creating independence and self-reliance is more sustainable.

The International Monetary Fund (IMF) has also highlighted inequitable access as a significant challenge in the global vaccine rollout programme. For example, on September 30th, 2021, Africa had administered the COVID-19 vaccine at the rate of 11.12 units per 100 people, ${ }^{8}$ far slower than the developed world average of 79.63 units per 100 individuals. Furthermore, widespread vaccine distribution is not expected in Africa until 2022 or even 2023, ${ }^{6}$ threatening vaccine targets set by the World Health Organisation for the African continent.

The Collaborative Africa Budget Reform Initiative $(\mathrm{CABRI})^{6}$ warns that traditional bilateral and multilateral development partners are unlikely to fully finance vaccine programmes for countries in need over the next two years or beyond. Governments must find ways to finance and distribute the short- and medium-term vaccine independently. Access to vaccines is expected to reduce the pandemic and economic burden, therefore emphasising vaccine program sustainability. CABRI recommends that African governments explore mechanisms to finance COVID-19 vaccines through domestic resource allocation. Options include budget reprioritisation, user fees, vaccine bonds, tax hikes and levies, and private sector support ${ }^{6}$. Donations only benefit the short-term; building a holistic vaccine manufacturing capacity is essential. For instance, Aspen's manufacturing plant ${ }^{9}$ in Gqeberha, South Africa, is now producing the first "fill and finish" doses of the Johnson \& Johnson vaccines, which were expected to be distributed in Africa. This has been celebrated as a step forward in assisting the continent with vaccine production capacity. However, the active pharmaceutical ingredients (API) needed for vaccine production must still be imported from Europe. Interestingly, it emerged that quantities of these vaccines are being shipped to Europe to assist with booster doses; meanwhile, most Africans remain unvaccinated, creating a moral dilemma. On the $2^{\text {nd }}$ December 2021, only $24.68 \%$ of the South African population was fully vaccinated compared to $68.07 \%$ in the UK and $59.13 \%$ in the US. ${ }^{10}$

Africans face double jeopady on life expectancy due to worsening worsening social determinants of health, and the impact of constrained vaccine access. The pandemic induced an increase in the crude death rate in South Africa from 8.7 deaths per 1000 people in 2020 to 11.6 deaths per 1000 people in $2021 .^{11}$ Access to vaccines is critically dependent on international solidarity and collaboration for the sustainability of vaccine programs. The relationship between the economy, physical and mental health should be highlighted when addressing vaccine access issues in Africa. It is then paramount that vaccine access in Africa is viewed as an instrument to assist her in reaching her potential through better health to stimulate economic recovery.

In her book 'Dead Aid', author Dambisa Moyo is graphic in stating that "aid is a disease pretending to be a cure. Aid has been and continues to be an unmitigated political, economic, and humanitarian disaster for most parts of the developing world. There is a better way for Africa."12

Barriers to equitable vaccine access must be dismantled for the sake of current and future generations. The required quantity of vaccine booster shots and the impact on Africa's health and socioeconomic standing are currently unknown. Africa's vaccine manufacturing, distribution and promotion capacity is essential for a holistic and, sustainable COVID-19 vaccine rollout program.

\section{ETHICS}

No ethics approval was needed for the writing of this article.

\section{FUNDING}

No funding received.

\section{AUTHORSHIP CONTRIBUTION}

Both authors contributed to the conception, drafting and writing of the article. Both authors provided critical feedback on the manuscript and have agreed to be accountable for all aspects of the work.

\section{CONFLICT OF INTEREST}

The authors completed the ICMJE Unified Competing Interest form at (available upon request from the corresponding author), and declare no conflicts of interest.

\section{CORRESPONDENCE}

Brenda Kubheka, Ethics and clinical risk lead, Health IQ Consulting, Johannesburg, South Africa and School of Public Health. She is a PhD candidate at the School of Public Health, University of the Witwatersrand, Johannesburg, South Africa.E-mail: brenda.k@wol.co.za

Tshowa Kabala, Research Assistant, Health IQ Consulting, Johannesburg, South Africa; e-mail:tshowakabala@icloud.com

\section{ACKNOWLEDGEMENTS}

We would like to thank Ms Nyasha Mugadza for assistance in the proofreading and editing of this manuscript.

Submitted: December 06, 2021 CET 


\section{REFERENCES}

1. Saleh M. Median age of the population of Africa from 2000 to 2020. Statista. Published online April 2021. Accessed October 11, 2021. https://www.statist a.com/statistics/1226158/median-age-of-the-populat ion-of-africa/

2. Goal 1: No poverty. United Nations Development Programme. Accessed October 11, 2021. https://ww w.africa.undp.org/content/rba/en/home/sustainabledevelopment-goals/goal-1-no-poverty.html

3. Schoch M, Lakner C. African countries show mixed progress towards poverty reduction and half of them have an extreme poverty rate above $35 \%$. World Bank Blogs. Published December 2020. Accessed October 11, 2021. https://blogs.worldbank.org/opendata/africa n-countries-show-mixed-progress-towards-poverty- $r$ eduction-and-half-them-have-extreme

4. Adepoju P. Beyond vaccine hesitancy: time for Africa to expand vaccine manufacturing capacity amidst growing COVID-19 vaccine nationalism. The Lancet Microbe. 2021;Volume 2:e347-e348. doi:10.101 6/s2666-5247(21)00126-9

5. Kretchmer H. Vaccine nationalism- and how it could affect us all. World Economic Forum. Published online January 2021. Accessed October 11, 2021. http s://www.weforum.org/agenda/2021/01/what-is-vaccin e-nationalism-coronavirus-its-affects-covid-19-pand emic/

6. The Collaborative Africa Budget Reform Initiative. Covid-19 Africa Public Finance Report Response Monitor. CABRI. Accessed October 11, 2021. https://w ww.cabri-sbo.org/uploads/files/Documents/CABRI-W orking-Paper-COVID-19-vaccine-financing-procurem ent-and-distribution-in-African-ministries-of-financ e-and-health.pdf
7. World Bank Support for Country Access to Covid-19 Vaccines. The World Bank Group Accessed October 11, 2021. https://www.worldbank.org/en/who-we-are/ news/coronavirus-covid19/world-bank-support-for-co untry-access-to-covid-19-vaccines

8. Faria J. Coronavirus (Covid-19) vaccination rate in Africa compared to the world from January 30th to October 7th, 2021. Statista. Published online 2021. Accessed October 11, 2021. https://www.statista.com/ statistics/1245573/covid-19-vaccination-rate-in-afric a-compared-to-the-world/

9. Monama T. “Significant landmark” for SA and Africa- Aspen's Gqeberha plant to release J\&J vaccines on Monday. News24 Updated July. Published online 2021. Accessed October 11, 2021. https://ww w.news24.com/news24/southafrica/news/significant-1 andmark-for-sa-and-africa-aspens-gqeberha-plant- $t$ o-release-ji-vaccines-on-monday-20210726

10. Coronavirus (Covid-19) vaccinations. Our World in Data. Accessed October 11, 2021. https://ourworldind ata.org/covid-vaccinations

11. Covid-19 epidemic reduces life expectancy in 2021. Stats SA. Published online July 2021. Accessed October 11, 2021. http://www.statssa.gov.za/?p=1451 $\underline{9}$

12. Moyo D. Dead Aid. Why aid is not working and how there is a better way for Africa. New York Times. Accessed June 2021. https://dambisamoyo.com/book/ dead-aid/ 